\title{
Molecular Mechanisms Underlying the Circadian Rhythm of Blood Pressure in Normotensive Subjects
}

\author{
Yves Lecarpentier $^{1}$ • Olivier Schussler ${ }^{2,3} \cdot$ Jean-Louis Hébert ${ }^{4} \cdot$ Alexandre Vallée $^{5}$
}

Published online: 13 July 2020

(C) The Author(s) 2020

\begin{abstract}
Purpose of Review Blood pressure (BP) follows a circadian rhythm (CR) in normotensive subjects. BP increases in the morning and decreases at night. This review aims at providing an up-to-date overview regarding the molecular mechanisms underlying the circadian regulation of BP.

Recent Findings The suprachiasmatic nucleus (SCN) is the regulatory center for CRs. In SCN astrocytes, the phosphorylated glycogen synthase kinase- $3 \beta$ (pGSK-3 $\beta$ ) also follows a CR and its expression reaches a maximum in the morning and decreases at night. pGSK- $3 \beta$ induces the $\beta$-catenin migration to the nucleus. During the daytime, the nuclear $\beta$-catenin increases the expression of the glutamate excitatory amino acid transporter 2 (EAAT2) and glutamine synthetase (GS). In SCN, EAAT2 removes glutamate from the synaptic cleft of glutamatergic neurons and transfers it to the astrocyte cytoplasm where GS converts glutamate into glutamine. Thus, glutamate decreases in the synaptic cleft. This decreases the stimulation of the glutamate receptors AMPA-R and NMDA-R located on glutamatergic post-synaptic neurons. Consequently, activation of NTS is decreased and BP increases. The opposite occurs at night.

Summary Despite several studies resulting from animal studies, the circadian regulation of BP appears largely controlled in normotensive subjects by the canonical $\mathrm{WNT} / \beta$-catenin pathway involving the $\mathrm{SCN}$, astrocytes, and glutamatergic neurons.
\end{abstract}

Keywords Arterial blood pressure · Canonical WNT/ $\beta$-catenin pathway $\cdot$ Glycogen synthase kinase $\cdot$ Astrocyte $\cdot$ Circadian rhythm $\cdot$ Suprachiasmatic nucleus $\cdot$ Glutamine synthetase, nucleus tractus solitarius

\section{Introduction}

Numerous physiological regulations vary rhythmically over the course of a 24-h day. Circadian rhythms (CRs) such as

This article is part of the Topical Collection on Blood Pressure Monitoring and Management

Yves Lecarpentier

yves.c.lecarpentier@gmail.com

1 Centre de Recherche Clinique, Grand Hôpital de l'Est Francilien, 77104 Meaux, France

2 Department of Thoracic surgery, Nouvel Hôpital Civil, Hôpitaux Universitaires de Strasbourg, Strasbourg, France

3 Department of Cardiovascular Surgery, Research Laboratory, Geneva University Hospital, Geneva, Switzerland

4 Cardiology Institute, Pitié-Salpétrière Hospital, AP-HP, Paris, France

5 Diagnosis and Therapeutic Center, Hypertension and Cardiovascular Prevention Unit, Paris-Descartes University, Hôtel-Dieu Hospital, AP-HP, Paris, France body temperature, sleep-wake cycles, metabolism, and blood pressure (BP) represent various examples of CRs. Although $\mathrm{BP}$ is relatively stable over time in normotensive subjects [1], it varies throughout the day, according to a CR [2-4]. Thus, $\mathrm{BP}$ starts to rise during the morning (morning surge), about $1 \mathrm{~h}$ prior to awakening and decreases at night [5]. Once the BP peak is reached, it remains elevated until late afternoon and starts to progressively decrease to reach a nadir around 3:00 (a 10-20\% dip). CRs in the brain, heart, kidneys, and arterial vessels prepare the transition from sleep to activity and adjust the cardiovascular system for optimal function [6]. An abnormal CR of the BP is considered to be an excellent predictor of adverse cardiac events [7-13]. Rhythmic variations in BP require great interest as several cardiovascular diseases, such as myocardial infarction, stroke, arrhythmia, and sudden cardiac death, are linked to CR dysregulations [14-16]. These events often occur in patients whose BP fails to decline during the night. Such patients are called non-dippers [13, 17]. In mammals, the central clock resides in the suprachiasmatic nucleus $(\mathrm{SCN})$ which is directly stimulated by light throughout the 
retinal hypothalamic tract (RHT). Peripheral clocks located in most other tissues throughout the body, are synchronized by the SCN in response to light and communicate via either neuronal or hormonal signals [18-20]. The disruption of normal day-night cycles, such as those induced by jet lag, leads to desynchronization between the central SCN clock and peripheral clocks [21]. BP follows a CR, independently of the sleep/ wake cycle or fasting/feeding [22]. If physical activity is increased during the night, the nocturnal decrease in $\mathrm{BP}$ is blunted. Thus, there is a link between the CR of BP and physical activity, showing that the sleep/awake ratio of BP is related to the night/day activity [7]. Shift works alter CRs. Shift workers, i.e., subjects working beyond the typical daily working hours, night shift, early morning shift, and rotational work have a higher chance of hypertension than day workers do [23]. The longer the workers work continuously, the higher the risk of hypertension.

In human normotensive subjects, the cellular and molecular mechanisms underlying the CR of arterial BP are not well understood and remain to be determined. This review focuses on the key role of the phosphorylation of the glycogen synthase kinase- $3 \beta$ (pGSK-3 $\beta$ ), a major component of the canonical WNT/ $\beta$-catenin pathway. The $\beta$-catenin-induced expression of the glutamate excitatory amino acid transporter 2 (EAAT2) and glutamine synthetase (GS) modulates the glutamate cycle [24•]. Importantly, pGSK-3 $\beta$ follows a CR in $\mathrm{SCN}$ astrocytes $\left[25^{\bullet}, 26^{\bullet}\right]$ that ultimately regulates the sympathetic/parasympathetic nervous activity and induces a circadian regulation of the arterial BP. Circadian variations of pGSK- $3 \beta$ in combination with those of EAAT2 and GS via the canonical WNT/ $\beta$-catenin signaling, but also with those of other pathways such as those of PI3K-Akt [27-29] and cMYC [30], contribute to a circadian modulation of the glutamate content in both the cytoplasm of astrocytes and in the synaptic cleft of the glutamatergic neurons in the SCN. Finally, the reuptake of glutamate by EAAT2 in the morning induces a reduction in its content in the synaptic cleft. This leads to a decrease in the activation of the nucleus tractus solitarius (NTS) and therefore to an increase in BP during the day. The opposite occurs at night.

\section{The Core Clock Genes}

CRs are biological processes displaying endogenous oscillations of about $24 \mathrm{~h}$. They are driven by a number of important clock genes. The core clock genes consist of BMAL1 (brain and muscle aryl-hydrocarbon receptor nuclear translocatorlike 1), CLOCK (Circadian Locomotor Output Cycles Kaput), PER (period), and CRY (cryptochrome) [31]. They are closely regulated and form interlocking feedback and feedforward loops. In the nucleus, BMAL1 and CLOCK proteins form a heterodimer that binds to E-box elements in their promoter regions. This activates the PER and CRY transcription. After accumulation in the cytoplasm, PER and CRY proteins heterodimerize and then translocate to the nucleus where they repress the CLOCK-BMAL1 regulatory complex, thereby inhibiting their own transcription. From the cytoplasm, the nuclear orphan receptors ROR $\alpha$ and REV-ERB $\alpha$ translocate to the nucleus. ROR $\alpha$ activates and REV-ERB $\alpha$ represses ROR-mediated transcription, forming the secondary autoregulatory feedback loops. REV-ERB $\alpha$ is activated by CLOCK-BMAL1 and feeds back to transcriptionally repress BMAL1. The activator clock genes (CLOCK and BMAL1) are expressed in anti-phase to the suppressor clock genes (PERs and CRYs). Duration of the circadian clock cycle can be regulated by post-translational events that include phosphorylation by kinases [32]. This whole complex system regulates the circadian rhythmicity of numerous biochemical pathways [31]. The central clock together with peripheral clocks within the kidneys, brain, heart, and vasculature play an important role in the circadian regulation of BP $[33,34]$.

\section{The Master Circadian Clock Suprachiasmatic Nucleus}

In mammals, SCN located in the hypothalamus is the master circadian clock that coordinates daily rhythms of behavior and metabolism [18]. SCN (Fig. 1) interacts with peripheral oscillators, drives, and synchronizes the daily activity of CRs to the light/dark cycle [19] via transcriptional-translational feedback loops resulting in rhythmic expression of the core clock genes. SCN synchronizes rhythms of clock gene expression in all body organs. Thus, the body is prepared in an optimal manner and adapted to daily changes in activity. The electrical activity of numerous SCN neurons presents CRs that induce a circadian secretion of neurotransmitters towards target areas of the body [35-37]. The SCN also imposes its own rhythm into the body through the autonomous nervous system. The SCN uses separate connections for the sympathetic and parasympathetic systems. Dysfunction of the SCN initiates cardiovascular diseases, particularly in several types of hypertension [38-40]. Postmortem analyses have reported abnormalities in the SCN of hypertensive humans and animals [41, 39, 42].

\section{Neuroanatomical Centers}

\section{The Retinal Hypothalamic Tract}

The ventrolateral SCN [43] is involved through light inputs coming from the retina via the RHT (Fig. 1). In mammals, RHT plays a key role in the regulation of CRs. RHT originates in the photosensitive retinal ganglion cells (ipRGC). The ipRGC axons of the RHT project directly to the SCN by 


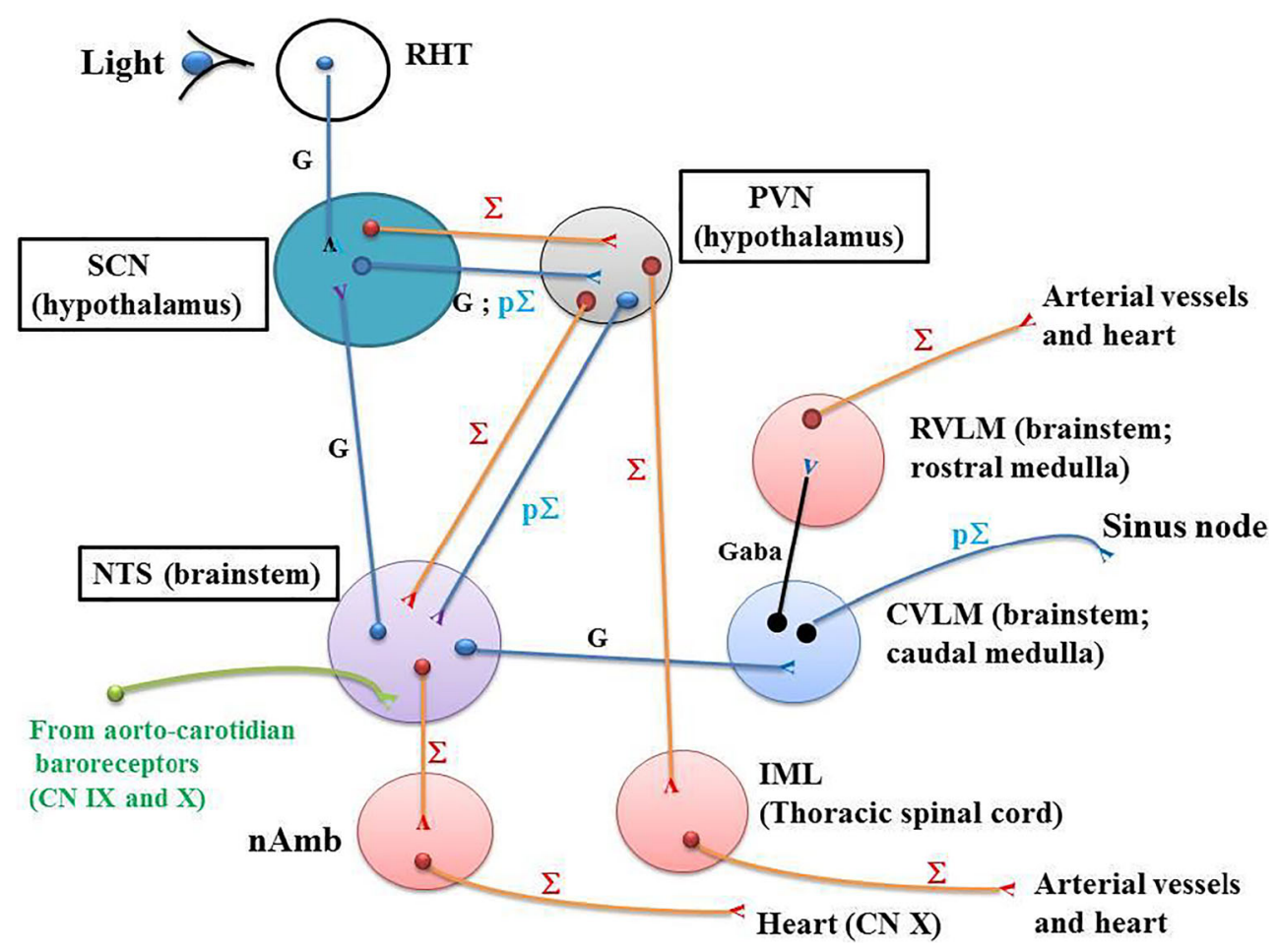

Fig. 1 Neuroanatomical network involved in the CR of BP. RHT: the retinohypothalamic tract (RHT) originates in the intrinsically photosensitive retinal ganglion cells (ipRGC) which project directly via monosynaptic and glutamatergic transmission to the ventrolateral SCN through the optic nerve and the optic chiasma. ipRGC relay photic information from the eyes to the SCN. SCN: the suprachiasmatic nucleus $(\mathrm{SCN})$ receives glutamatergic neurons from both RHT and nucleus tractus solitarius (NTS). SCN projects glutamatergic preautonomic parasympathetic neurons to the PVN. Separate preautonomic sympathetic or parasympathetic neurons project to preautonomic neurons of the PVN. PVN: paraventricular nucleus (PVN) receives pre-autonomic sympathetic and parasympathetic neurons from the SCN. PVN projects pre-ganglionic sympathetic neurons in the IML. Moreover, pre-autonomic sympathetic neurons in the PVN present axon collaterals to pre-autonomic parasympathetic neurons in the PVN itself and to the NTS $[47 \cdot, 55]$. NTS: nucleus tractus solitarius (NTS) which is located in the brainstem receives neuronal informations from the aortic and carotid baroreceptors which are stimulated after a rapid increase in BP. The carotid sinus baroreceptor axons travel within the glossopharyngeal nerve. The aortic arch baroreceptor axons travel within the vagal nerve. Baroreceptor activity travels along these nerves directly to the NTS. Then, the neuronal activity flows from NTS to both parasympathetic and sympathetic neurons within the brainstem. The NTS neurons send glutamatergic excitatory fibers to the caudal ventrolateral medulla (CVLM). The GABAergic activated CVLM then sends inhibitory fibers to the rostral ventrolateral medulla (RVLM), thus inhibiting the RVLM. The sympathetic and parasympathetic branches of the autonomic nervous system have opposite effects on BP. When

means of a monosynaptic junction to the SCN through the optic nerve and the optic chiasma. They relay photic information from the eyes to the SCN. Light-induced information enters the ventrolateral SCN. Light activation of RHT makes it possible for CRs to adjust to the bright or dark environment. $\mathrm{SCN}$ receives and interprets information according to the level of environmental light. Retinal nerve terminals contain a the aortic and carotid baroreceptors are activated by an increase in BP, NTS activates CVLM, which in turn inhibits the RVLM. This decreases the activity of the sympathetic branch of the autonomic nervous system, leading to a decrease in BP. Conversely, a decrease in BP decreases baroreceptor activation and induces an increase in sympathetic tone via "disinhibition" of the RVLM. CVLM: caudal ventrolateral medulla (CVLM). The ventrolateral medulla consists of the caudal ventrolateral medulla (CVLM) and the rostral ventrolateral medulla (RVLM). The ventrolateral medulla, part of the medulla oblongata of the brainstem, plays a major role in regulating arterial BP. CVLM receives neurons from the NTS and projects GABA fibers towards RVLM, which in turn inhibits the activity of the RVLM. RVLM: rostral ventrolateral medulla (RVLM). Neurons in the RVLM project directly to pre-ganglionic neurons in the spinal cord (intermediolateral nucleus: IML) which maintain tonic activity of the sympathetic vasomotor nerves. The RVLM is the primary regulator of the sympathetic nervous system, sending glutamatergic excitatory fibers to the sympathetic preganglionic neurons located in the IML of the spinal cord. IML: the intermediolateral nucleus (IML) is located in the lateral grey column of the spinal cord and mediates the entire sympathetic innervation of the body. It receives neurons from the RVLM. nAmb: the nucleus ambiguus (nAmb) is located in the medullary reticular formation and gives rise to efferent motor fibers of the vagal nerve $(\mathrm{CN} \mathrm{X})$. These fibers are cardio-inhibitory allowing rapid BP changes in response to fast increases in BP. The parasympathetic outflow arising from nAmb acts to decrease cardiac activity in response to fast increases in BP. nAmb receives fibers from NTS. Symbols: $\Sigma$; sympathetic (red); $\mathrm{p} \Sigma$ : parasympathetic (blue); G: glutamatergic neurons

significant concentration of glutamate. Light acts as a zeitgeber, which is an external or environmental cue that synchronizes biological rhythms to the Earth's 24-h light/dark cycle, 12-month cycle, etc. Light thus induces a powerful effect on the SCN. Glutamate, a key neurotransmitter, is stored in a subpopulation of ipRGC projecting to the retinal-recipient zone of the ventrolateral SCN. Glutamate mediates light 
signaling to the SCN. Glutamate and glutamate agonists such as N-methyl-D-aspartate mimic light-induced phase shifts. A glutamate immune reactivity within presynaptic nerve terminals has been reported in the rat SCN $[44,45]$. In the SCN, the targets of glutamate are the clock genes PER1 and PER2, which are influenced by light [46].

\section{The Suprachiasmatic Nucleus}

The ventrolateral SCN receives direct glutamatergic projections from the caudal nucleus tractus solitaries (NTS) controlling the cardiovascular areas (Fig. 1). This provides a key neuroanatomical link between NTS and SCN for the involvement of the ventrolateral SCN in the short-term control of BP. These neurons are glutamatergic ones $\left[47^{\circ}\right]$. This has been corroborated by experiments in which either NTS or SCN is lesioned. Thus, a BP rise induced by an $\alpha 1-$ agonist infusion in animals leads to an increase in neuronal activity in both caudal NTS and ventrolateral SCN. Lesioning in the caudal NTS prevents this neuronal activity $\left[47^{\circ}\right]$. Other studies have also shown that damages of the caudal NTS drastically impair the short-term adaptation of BP after administration of a vasoactive agent [48, 49]. Importantly, the BP rise induced by a vasopressive stimulus increases to more than twice the BP level observed in SCN-lesioned animals [47•]. This demonstrates the role of the $\mathrm{SCN}$ in counteracting a rise in $\mathrm{BP}$ and in the short-term regulation of BP. Thus, the NTS-SCN neuroanatomical connection (Fig. 1) damps down the BP increase after a vasopressive stimulus. Moreover, SCN lesions alter the 24-h BP variability in rats [50]. The ventrolateral SCN adapts its response according to the BP information that originates in the caudal NTS. The SCN receives feedback on the cardiovascular status via the NTS. The NTS is itself the major integrative site towards which a large amount of peripheral information converges from both aortic and carotid baroreceptors (Fig. 1). Activation of the ventrolateral SCN through caudal NTS neuronal projections stimulated by an increase in BP or through light-RHT-SCN activation leads to a similar pattern [51]. Moreover, SCN projects pre-autonomic sympathetic and parasympathetic neurons to the paraventricular nucleus (PVN) [47•]. SCN balances separate pre-autonomic sympathetic and parasympathetic neurons to peripheral organs [52]. Thus, the ventrolateral SCN provides a quadruple function: (i) SCN coordinates the regulation of CRs [20]. SCN synchronizes the peripheral clock genes involved in the cardiovascular control, comprising arterial blood vessels, kidneys, and adrenal glands [53, 54]; (ii) SCN damps down a BP increase via the complex NTS-SCN-PVN neuroanatomical network [47]; (iii) SCN is activated by light via RHT glutamatergic neurons [51]; (iv) SCN exports glutamatergic neurons to the PVN.

\section{The Paraventricular Nucleus}

PVN exports pre-autonomic sympathetic neurons to NTS and the intermedio-lateralis nucleus (IML). Pre-autonomic sympathetic neurons in PVN have collaterals that project to preautonomic parasympathetic neurons in the NTS [52, 55, 47•] (Fig. 1). There are reciprocal connections between neurons in the NTS and the PVN. This shows that the PVN is involved in the neural control of the cardiovascular system [56]. Certain neuronal projections from the PVN to the NTS are glutamatergic [57].

\section{The Nucleus Tractus Solitarius (NTS)}

The NTS, located in the brainstem (Fig. 1) is central in the short-term BP regulation and represents a key element of the baroreflex loop. The most sensitive baroreceptors are located in both the carotid sinuses and the aortic arch. The baroreceptor activity travels along the glossopharyngeal nerve and vagal nerve up to the NTS. NTS neurons send glutamatergic excitatory fibers to the caudal ventrolateral medulla (CVLM). The activated CVLM then sends inhibitory GABAergic fibers to the rostral ventrolateral medulla (RVLM) which is the primary regulator of the sympathetic nervous system. RVLM sends excitatory fibers to the sympathetic pre-ganglionic neurons located in the IML of the spinal cord (Fig. 1). An increase in BP activates baroreceptors which results in stimulating the activity of neurons in the caudal NTS [58, 59]. Then, NTS activates the CVLM via glutamatergic fibers which increases the activity of the parasympathetic branch of the autonomic nervous system, and in turn inhibits the RVLM, thus decreasing the activity of the sympathetic branch of the autonomic nervous system. This leads to a decrease in BP. Conversely, a decrease in BP deactivates baroreceptors leading to an increase in sympathetic tone via "disinhibition" of the RVLM and an increase in BP.

\section{Light-Induced Effects on the SCN}

The environmental light which is provided by the day-night cycle impacts on CRs through both RHT and SCN, controlling the homeostasis of blood glucose level, water balance, and body temperature $[20,60,61]$. Importantly, the autonomic nervous activity is modified after light exposure, an effect that disappears after SCN lesioning [62, 63]. Light, through RHT and SCN, enhances sympathetic activity and suppresses vagal outflows, whereas SCN lesions eliminate these changes [20]. The autonomic nervous system contributes to the CR of BP $[64,65]$. However, connections between light-induced molecular events and neurophysiological excitability have not been definitively identified [66]. GSK-3 $\beta$ appears to play a key role in the regulation of mammalian CRs and particularly in the phosphorylation of several components of the core-molecular 
clock [26•, 67, 68]. Chronic pGSK-3 $\beta$ activation increases SCN neuronal activity, whereas inhibition of $\mathrm{pGSK}-3 \beta$ diminishes it, highlighting pGSK-3 $\beta$ as a regulator of neurophysiological CRs $[69,70]$. Importantly, in the SCN, GSK$3 \beta$ regulates the photic signaling [71]. In the SCN, we have seen earlier that pGSK-3 $\beta$ exhibits a CR with maximum activity in the morning at ZT2. It then progressively decreases during the daytime, until it reaches a minimum at night ZT14, after which it begins to increase again [26•]. Light is an important entraining signal to the SCN $[72,73]$. At specific times in the night, exposure to light shifts the phase of the molecular clock and behavioral CR [73]. In response to an acute lightpulse, the phase-resetting mechanism induces a glutamate release from the RHT onto SCN neurons [74, 75, 46] and activation of NMDA receptors [76, 77]. In mice $S C N$, a late-night exposure to light significantly increases the GSK-3 $\beta$ activity (corresponding to a decreased pGSK-3 $\beta$ level), which occurs 30-60 min after a light-pulse [71]. Thus, GSK-3 $\beta$ activation mediates light-induced SCN excitability and photic entrainment [71]. Conversely, inhibition of GSK-3 $\beta$ blocks the light-induced excitability in SCN neurons. Moreover, GSK$3 \beta$ activation is necessary for light-induced SCN neuronal activity [71]. These results are consistent with those from other studies that have shown a light-induced decrease in the number of $\mathrm{pGSK} 3 \beta$ positive cells in rat SCN [78]. GSK-3 $\beta$ regulates CRs in SCN excitability through the modulation of a persistent sodium current (INaP) [70]. Optogenetic stimulation of SCN neurons alone is sufficient to shift CRs, mimicking the effects of a light-pulse [79]. GSK-3 $\beta$ dysregulation has been found to be associated with chronic night lightning exposure and to be linked with several disorders such as depression [80], obesity [81, 82], and cancer [83].

\section{GSK-3 $\beta$ in SCN Astrocytes}

pGSK $-3 \beta$ is a major component of the destruction complex in the canonical WNT/ $\beta$-catenin pathway [84-87] (Figs. 2 and 3 ). The phosphorylated form (pGSK-3 $\beta$ ) activates this pathway and the non-phosphorylated form (GSK-3 $\beta$ ) inhibits it. In SCN astrocytes, pGSK-3 $\beta$ allows the release of $\beta$-catenin from the destruction complex. Cytoplasmic $\beta$-catenin then migrates from the cytoplasm to the nucleus of SCN astrocytes. The nuclear $\beta$-catenin links the co-transcription factors TCF/ LEF. This leads to an increase in the expression of both EAAT2 and GS in astrocytes [24•]. This makes it possible the transport of glutamate from the synaptic cleft to the cytoplasm of SCN astrocytes and, consequently, this lowers the glutamate content in the synaptic cleft thereby decreasing activation of NMDA-R and AMPA-R located in the postsynaptic glutamatergic neuron, the stimulation of which is diminished (Figs. 2 and 3).

The two GSK-3 isoforms, i.e., GSK- $3 \alpha$ and GSK-3 $\beta$, are inactivated by phosphorylation at Ser-21 for GSK-3 $\alpha$ (S21-
GSK-3 $\alpha$ ) and Ser-9 for GSK-3 $\beta$ (S9-GSK-3 $\beta$ ). Importantly, in the SCN, both phosphorylated GSK-3 $\alpha$ (pGSK-3 $\alpha$ ) and phosphorylated GSK-3 $\beta$ (pGSK-3 $\beta$ ) isoforms show circadian variations. The phosphorylation state of S9-GSK-3 $\beta$ changes through the light-dark cycle $[25 \bullet, 26 \bullet$. In the SCN, the pGSK$3 \beta$ isoform (inactive state) presents a CR [25•, 26•, 88]. Circadian changes in total pGSK-3 $\beta$ content are undetectable, but importantly, the phosphorylation level at Ser-9 (S9-GSK$3 \beta$ ) changes in a circadian manner in both SCN and liver and can be measured [26•]. This suggests that the rhythmic phosphorylation of pGSK-3 $\beta$ at Ser-9 is regulated by the SCN master clock center, while the liver peripheral clock is regulated via a systemic control from the SCN. The significant CR of both phosphorylated GSK- $3 \alpha$ and GSK-3 $\beta$ has also been observed in the SCN from wild-type mice housed in constant darkness for 2 weeks [88]. The persistence of the CR of pGSK-3 $\beta$ in the absence of light argues for an intrinsic clock regulation. GSK-3 directly phosphorylates at least five core clock proteins, i.e., CLOCK, BMAL1, PER2, CRY2, and REV-ERB $\alpha$ [89, 90, 67, 68]. BMAL1 undergoes various post-translational modifications and is specifically phosphorylated by GSK-3 $\beta$ on Ser 17 and Thr 21. In the absence of GSK-3 $\beta$-mediated phosphorylation, BMAL1 becomes stabilized and its gene expression is dampened. This makes it possible to control the stability of BMAL1 as well as the amplitude of the CR. BMAL1 phosphorylation is a key regulatory mechanism in maintaining the robustness of the CR [68].

\section{Astrocytes Regulate CRs in SCN [91-93]}

$\beta$-Catenin signaling positively regulates glutamate uptake in SCN astrocytes [24•]. The glutamate/glutamine cycle plays a major role in the brain homeostasis. Glutamate is the most abundant neurotransmitter in the brain and is involved in learning, memory, and cognition. The regulation of the glutamate cycle involves two major elements: (i) glutamate transporter EAAT2 in humans and glutamate transporter GLT-1 in rodents, and (ii) GS. Glutamate is released from the presynaptic part of the neuron towards the synaptic cleft. The astrocyte membrane contains EAAT2 transporters which are assigned to clear glutamate from the synaptic cleft towards the astrocyte cytoplasm (Figs. 2 and 3). Then, glutamate is converted into glutamine by GS that is exclusively expressed in astrocytes [94] and that catalyzes the ATP-dependent reaction of glutamate and ammonia into glutamine. Glutamine is released from astrocytes and in turn is taken up by the presynaptic neuron to be converted back to glutamate by a glutaminase. Astrocytes play a major role in the excitatory pathway and clear more than $90 \%$ of glutamate excess $[95,96]$. EAAT2 is primarily expressed on astrocytes, and is the major transporter of glutamate into astrocytes [97, 98]. 


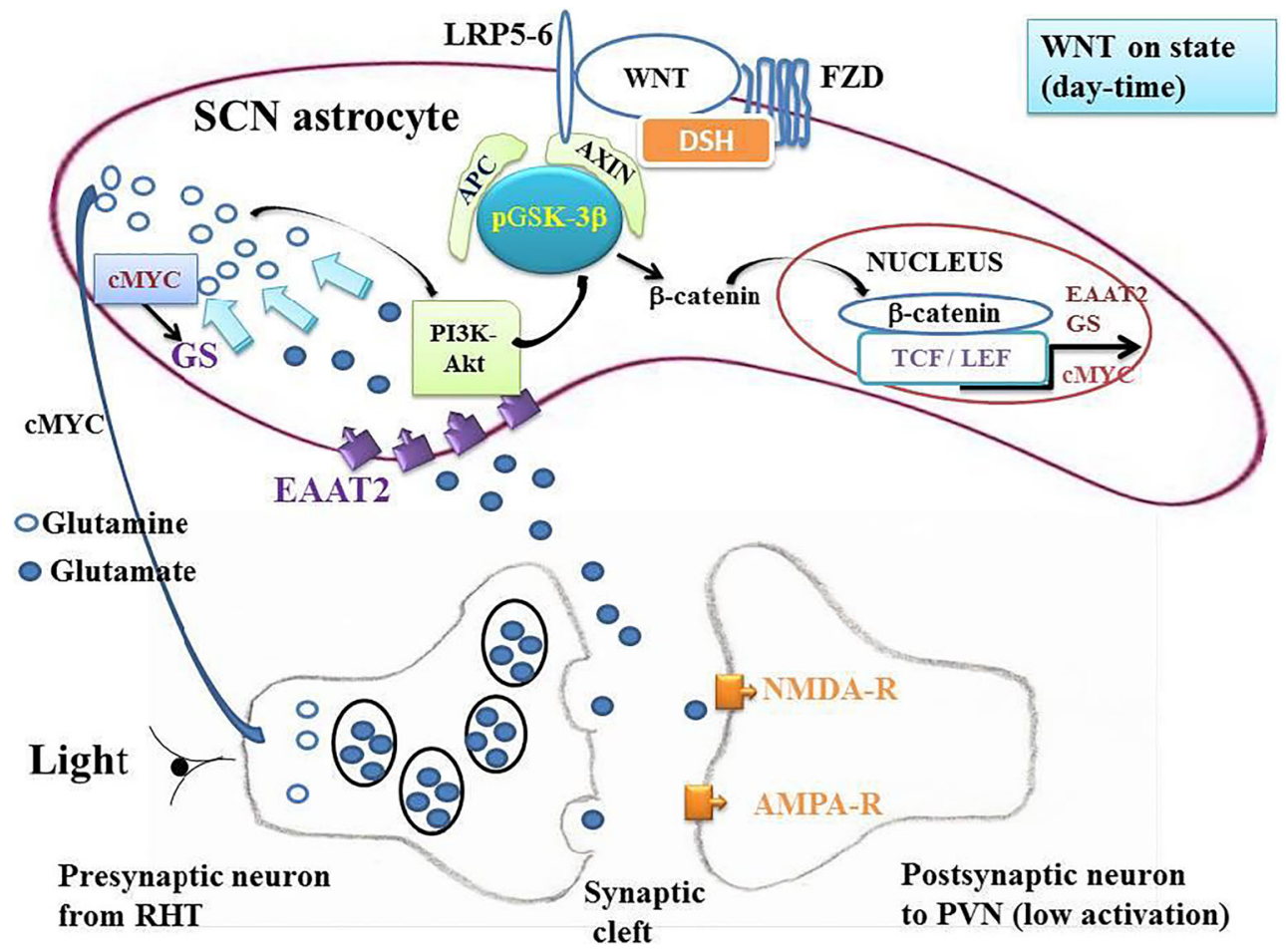

Fig. 2 Phosphorylated glycogen synthase kinase- $3 \beta$ (pGSK- $3 \beta$ ) and canonical WNT/ $\beta$-catenin signaling in "on" state. The canonical WNT pathway is "on-state" in the presence of the inactive phosphorylated form of the glycogen synthase kinase- $3 \beta$ (pGSK-3 $\beta$ ). Phosphorylation of GSK-3 $\beta$ can be induced either by WNT ligands or by other molecular mechanisms and particularly by light. On the one hand, a WNT ligand binds both FZD and LRP5/6 receptors. GSK-3 $\beta$ is then under the inactive phosphorylated form pGSK- $3 \beta$. This leads to activation of the phosphoprotein Disheveled (DSH). DSH recruits the destruction complex (pGSK-3 $\beta+$ AXIN +APC) to the plasma membrane, where AXIN directly binds the cytoplasmic tail of LRP5/6. APC is the adenomatous polyposis coli. On the other hand, expression of pGSK$3 \beta$ follows a circadian rhythm and reaches a maximum in the morning at ZT2. In both mechanisms, $\beta$-catenin is detached from the destruction

\section{EAAT2 and GS in SCN Astrocytes}

$\beta$-Catenin is a transcriptional co-activator and a key mediator of the canonical WNT/ $\beta$-catenin pathway (Figs. 2 and 3). It positively regulates EAAT2 and GS at the transcriptional level in human progenitor-derived astrocytes (PDAs) by partnering with $\mathrm{T}$ cell factors 1 and 3 (TCF-1 and TCF-3) [24•]. $\beta$ Catenin knockdown results in a decrease in the EAAT2 and GS expression in the prefrontal cortex. EAAT2 and GS are responsible for excitatory glutamate neurotransmission and the glutamate cycle in vitro and in vivo. Disruption of the canonical WNT/ $\beta$-catenin signaling leads to the modification of at least 128 genes [99]. Both in vitro and in vivo, disruption of $\beta$-catenin induces a dramatic inhibition of the glutamate transport network (EAAT2/GS) within astrocytes.

A modified WNT/ $\beta$-catenin pathway together with neuroinflammation has been described in aged rats and HIV patients $[100,101]$. An abnormal $\beta$-catenin pathway impacts the complex, accumulates into the cytosol, and then translocates to the nucleus to bind the LEF-TCF co-transcription factors. This induces the WNT-response gene transcription of numerous genes such as EAAT2, GS, and cMYC. This favors the re-uptake of glutamate from the synaptic cleft to the cytoplasm of astrocytes. This leads to a decrease of glutamate content in the synaptic cleft and a decrease of the activation of NMDA-R and AMPA-R, which are receptors located in the synaptic part of the glutamatergic post-synaptic neuron. SCN neurons project to the NTS via $\mathrm{PVN}$ and consequently decrease the parasympathetic tone and increase the sympathetic tone which favors the increase in BP in the morning when the expression of pGSK-3 $\beta$ is increased. $\beta$-Catenin increases the expression of cMYC. cMYC stimulates GS. Glutamine in the SCM astrocyte cytoplasm stimulates the PI3K-Akt pathway. The PI3K-Akt pathway phosphorylates GSK-3 $\beta$

EAAT2/GS expression and ultimately induces a glutamate excitotoxicity that represents a common neuropathological pathway for neuroinflammation and neurodegeneration. Anomalies in $\beta$-catenin regulation of both EAAT2 and GS have been reported in mouse hepatocellular carcinoma and human pancreatic tumors [102-104]. Numerous dysfunctions in the glutamate cycle have been reported. Thus, impairment of the EAAT2 function has been observed in acquired immune deficiency syndrome, amyotrophic lateral sclerosis, Alzheimer's disease, epilepsy, and ischemia/stroke [101, 105-117]. An excess of glutamate is neurotoxic and leads to numerous neurodegenerative diseases such as Alzheimer's disease $[118,119]$ and Parkinson's disease [120, 121].

\section{Phosphorylation of GSK-3 $\beta$}

The PI3K-Akt pathway activates the phosphorylation of GSK-3 $\beta$. Akt is activated by the phosphatidylinositol 3- 
Fig. 3 Unphosphorylated glycogen synthase kinase- $3 \beta$ (GSK-3 $\beta$ ) and canonical WNT/ $\beta$-catenin signaling in "off" state. Due to the decrease in the phosphorylation of pGSK-3 $\beta$ at night, the unphosphorylated form GSK- $3 \beta$ increases. This occurs at night reaching a nadir at ZT14. The canonical WNT pathway becomes in "off-state." The cytosolic $\beta$-catenin is phosphorylated and undergoes the destruction process into the proteasome. This decreases the expression of EAAT2, GS, and cMYC. Thus, the re-uptake of glutamate into the SCN astrocyte cytoplasm decreases and the glutamate content increases in the synaptic cleft, leading to an augmentation of NMDA-R and AMPA-R activation. This leads to an increase in parasympathetic tone and a diminution of the sympathetic tone and in fine a decrease in $\mathrm{BP}$ at night.

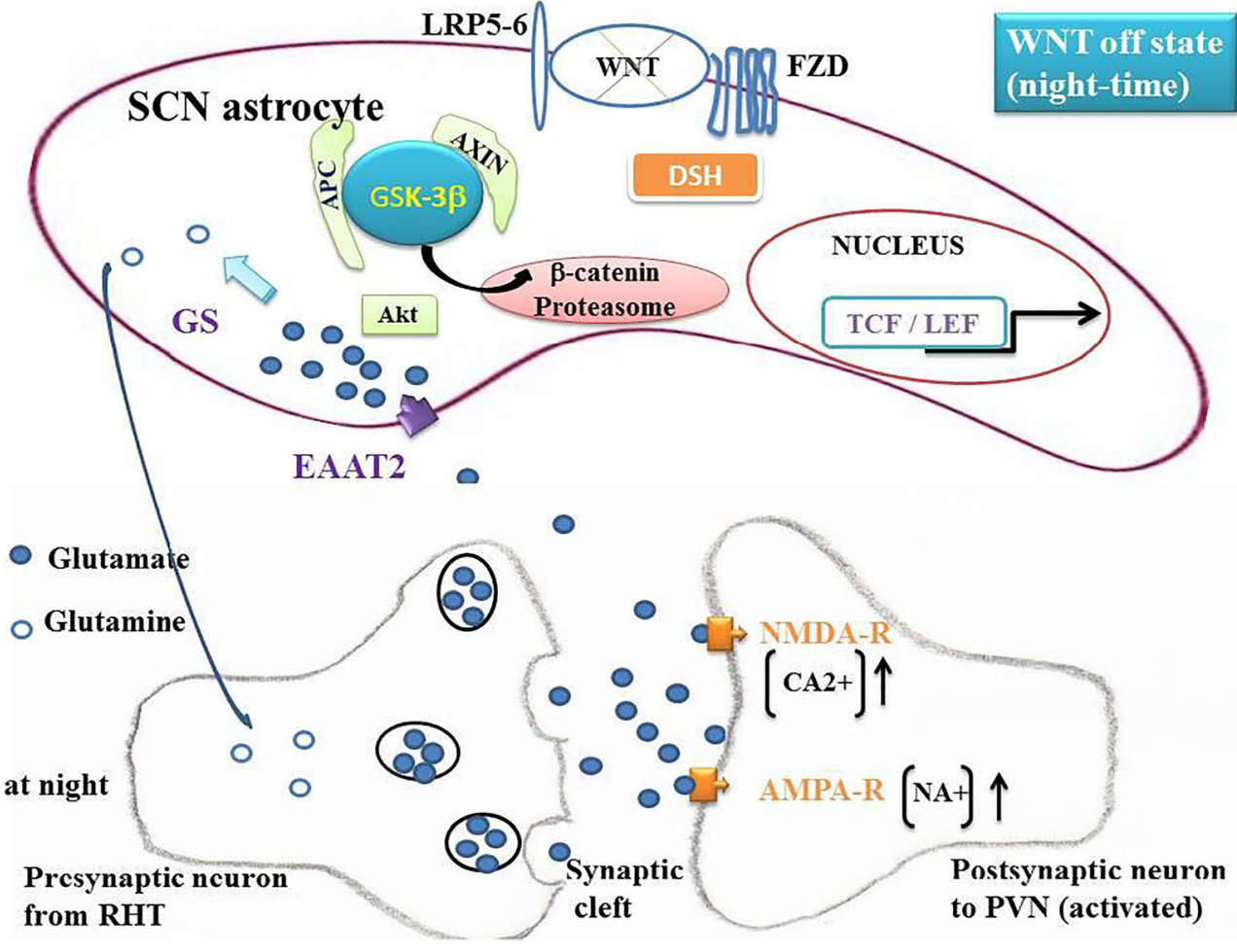

kinase (PI3K) signaling. Akt inhibits the active form GSK3- $\beta$ and activates the inactive form pGSK-3 $\beta$ [29]. As previously seen, this makes it possible the release of $\beta$-catenin in the astrocyte cytoplasm and its translocation in the nucleus leading to the $\beta$-catenin-induced expression of EAAT 2 and GS. In the brain, glutamate induces a rapid, reversible, and dose- and time-dependent loss of Akt-1 phosphorylation and kinase activity $[27,122]$.

Early in the morning and during the day, pGSK-3 $\beta$ activates the $\beta$-catenin signaling. This requires that the PI3K-Akt pathway is activated, since PI3K-Akt phosphorylates GSK-3 $\beta$ and that the glutamate content is low, as glutamate inhibits the PI3K-Akt pathway [27] and consequently inhibits pGSK-3ß. Since the expression of both EAAT2 and GS is increased during the daytime period, it is necessary that the transformation of glutamate into glutamine by GS is greater than or equal to the glutamate uptake by EAAT2. Moreover, $\beta$-catenin increases the expression of GS but also that of cMYC which itself also activates GS [30]. A relatively low glutamate level is required in the cytoplasm of SCN astrocytes. Moreover, glutamine activates PI3K-Akt [28], which perennializes activation of the canonical WNT signaling during the day. This pathway decreases or reverses during the night until ZT14 when pGSG-3 $\beta$ reaches a nadir. The glutamate content in astrocytes depends on the relative interaction between the EAAT2 activity which tends to increase glutamate content in astrocytes and the GS activity which tends to diminish it. At ZT2, pGGK- $3 \beta$ is maximum and the expression of EAAT2 increases [26•]. Consequently, the re-uptake of glutamate in the astrocyte cytoplasm increases, whereas glutamate in the synaptic cleft decreases, leading to lowering of the activation of glutamate receptors (AMPA-R and NMDA-R). Thus, activation is decreased in the pre-autonomic parasympathetic neurons projecting from the $\mathrm{SCN}$ to the PVN. This results in a decrease in the NTS activation, leading to a decrease in the parasympathetic (CVLM) tone and an increase in the sympathetic tone (RVLM), thus leading in an increase in BP during the daylight period. The opposite happens at night.

\section{A Model of the Circadian Rhythm of BP in Normotensive Subject (Fig. 4)}

GS catalyzes glutamate into glutamine and glutamine promotes the activity of the protein kinase Akt in vivo [28] (Figs. 2 and 3). Thus, an increase in glutamine content in the astrocyte cytoplasm activates PIK3-Akt and consequently favors the phosphorylation of GSK- $3 \beta$ - and the $\beta$-catenindependent expression of both EAAT2 and GS. Moreover, the $\mathrm{WNT} / \beta$-catenin signaling stimulates c-MYC expression [123]. It is also important to note that cMYC stimulates the expression of GS [30]. Thus, GS activity is promoted by the $\beta$-catenin-dependent increased expression of both GS and cMYC. cMYC activates GS activity and glutamine overproduction activates Akt activity. During the daytime, the high GS activity in the astrocyte cytoplasm makes it possible to maintain a low cytoplasmic glutamate content, a high glutamine content, and a high level of Akt-dependent level of phosphorylated GSK-3 $\beta$. GSK- $3 \beta$ phosphorylation, Akt 
activation, cMYC activation, and nuclear $\beta$-catenin levels vary in a parallel manner and decrease from ZT2 to ZT14 (Fig. 4). Glutamate content in astrocyte is the difference between the EAAT2 uptake capacity and the GS activation. High glutamate content in the astrocyte cytoplasm inhibits the PI3K-Akt pathway and consequently the GSK-3 $\beta$ phosphorylation which decreases from ZT2 to ZT14. EAAT2 and GS vary parallel to pGSK-3 $\beta$ with a short delay (Fig. 4). Glutamate content in the synaptic cleft activates the SCN glutamatergic post-synaptic neurons projecting to the PVN, and subsequently to the NTS. This favors the parasympathetic tone and inhibits the sympathetic tone, leading to a decrease in BP at night. The glutamate content in the synaptic cleft decreases from ZT3 to ZT15, which decreases the parasympathetic tone and increases the sympathetic tone, leading to an increase in BP during the daytime (Fig. 4).

\section{Thermodynamics and BP}

BP follows a CR and from a thermodynamic point of view, CRs are dissipative structures. This term has been first used by Ilya Prigogine [124] to characterize complex structures created by irreversible processes occurring far from equilibrium.
Such conditions can produce oscillations and can drive certain systems to organized states [125]. Irreversible processes generate entropy, which is commonly thought to be disorder. Surprisingly, the same irreversible processes can also produce self-organization, and dissipative structures [126, 127]. These concepts apply to temporal and sustained oscillations [128-130]. This makes it possible to bring together within a common formalism the great variety of rhythms and particularly CRs, reported at different levels of the biological organization, independently of numerous underlying mechanisms. CRs control major physiological functions, and their dysfunction can lead to numerous pathological states. They predict when sunlight will return, and this makes it possible the appropriate orchestration of the entire physiological machinery before sunrise. This leads to a competitive advantage. In terms of thermodynamic, this can modify the total entropy production rate compared to systems that lack such anticipatory control. Relating the entropy production rate to irreversible processes is of major importance. In the modern thermodynamics formulation, the change in entropy $\mathrm{dS}$ is the sum of two parts: $\mathrm{dS}=\mathrm{d}_{\mathrm{e}} \mathrm{S}+\mathrm{d}_{\mathrm{i}} \mathrm{S},\left(\mathrm{d}_{\mathrm{i}} \mathrm{S} \geq 0\right)$, in which $\mathrm{d}_{\mathrm{e}} \mathrm{S}$ is the entropy change due to exchange of matter and energy with the exterior of the system and $\mathrm{d}_{\mathrm{i}} \mathrm{S}$ is the entropy change due to irreversible

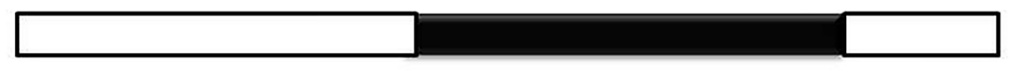
ZT0 ZT2 ZT3
ZT14 ZT15
ZT0 ZT2 ZT3

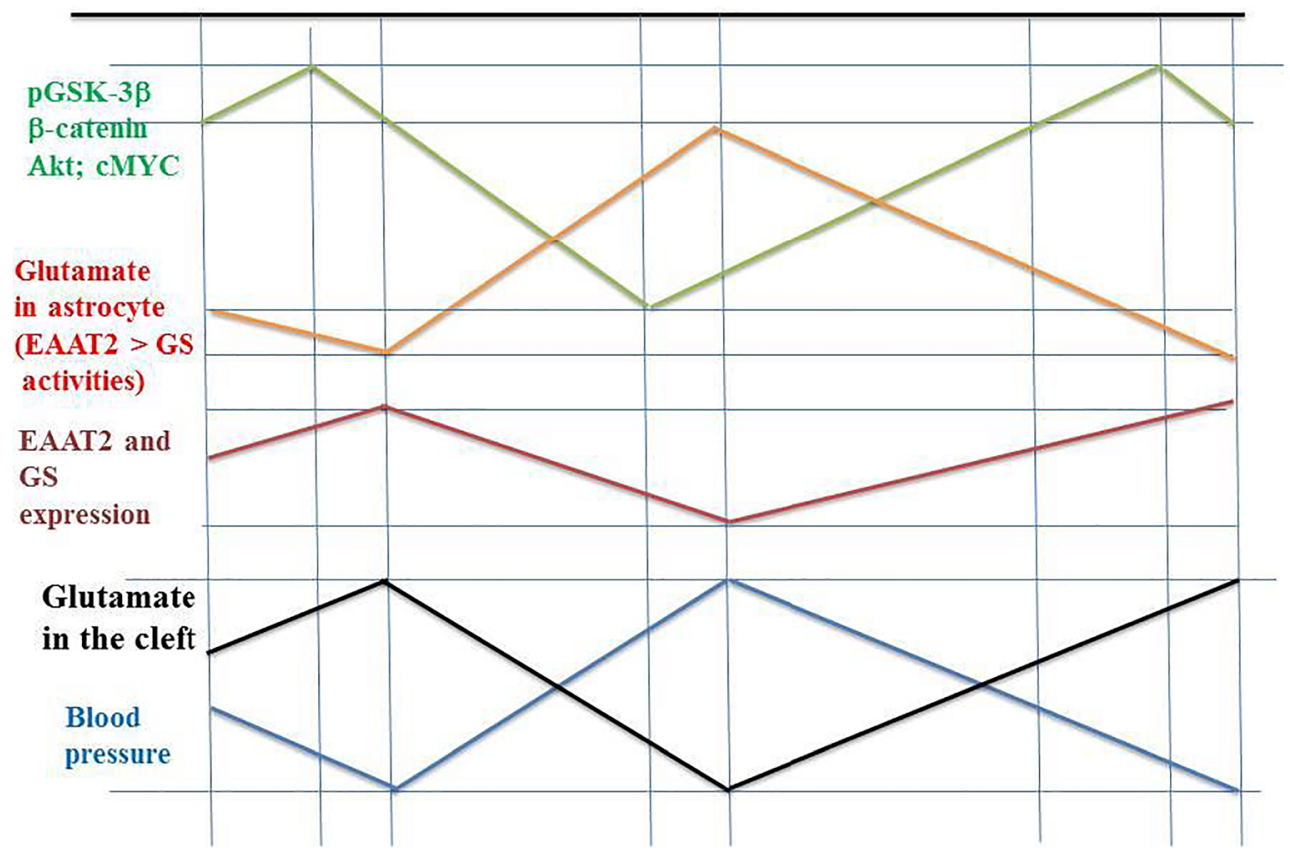

Fig. 4 Simplified model of the CR of the BP. pGSK-3 $\beta$, Akt activation, and nuclear $\beta$-catenin vary in a parallel manner and decrease from ZT2 to ZT14. Glutamate astrocyte content is the difference between EAAT2 activity and GS activation. Glutamate content in astrocyte cytoplasm inhibits the Akt pathway and consequently the GSK-3 $\beta$ phosphorylation which progressively decreases from ZT2 to ZT14. EAAT2 and GS vary in parallel with pGSK-3 $\beta$, but with a short delay.
Glutamate content in the synaptic cleft activates the SCN glutamatergic neurons projecting to the PVN and subsequently to the NTS. This increases the parasympathetic tone and inhibits the sympathetic tone, leading to decrease BP during the night. The glutamate content in the cleft progressively decreases from ZT3 to to ZT15, which decreases the parasympathetic tone and increases the sympathetic tone, resulting in an increase in BP during the daytime 
processes within the system. Irreversible processes can be expressed in terms of thermodynamic flows and thermodynamic forces. The entropy production rate due to all the irreversible processes is the product of a thermodynamic force $(F)$ and a thermodynamic flow $(J)$, leading to the equation $\mathrm{d}_{\mathrm{i}} \mathrm{S} /$ $\mathrm{dt}=F \times J[125,131]$. In mammal hemodynamics, the arterial blood pressure (BP), which is a controlled variable, is the product of the thermodynamic force $R$ (peripheral arterial resistances) and the thermodynamic flow $Q$ (cardiac output). Thus, $\mathrm{d}_{\mathrm{i}} \mathrm{S} / \mathrm{dt}=\mathrm{BP}=\mathrm{Q} \times \mathrm{R}$. The decrease in $\mathrm{BP}$ overnight leads to a decrease in the rate of entropy production and therefore is accompanied by a decrease in irreversible processes. This represents a considerable thermodynamic advantage in animal species where BP follows a circadian rhythm. The disappearance of the circadian regulation of BP amplifies the genesis of irreversible processes and promotes the occurrence of many pathologies in humans.

\section{Conclusions}

Although numerous studies cited in this review have been carried out in animals, we observe that the canonical WNT/ $\beta$-catenin pathway plays a central role in accounting for the circadian variation of BP in the normotensive subject. The crucial factor explaining the $\mathrm{CR}$ of $\mathrm{BP}$ is the circadian regulation of $\mathrm{pGSK}-3 \beta$ in SCN astrocytes. Light stimulates the sympathetic nervous system and inhibits the parasympathetic nervous system through the SCN. SCN astrocytes generate a complex mechanism in which the canonical WNT/ $\beta$-catenin pathway participates through the phosphorylation of GSK-3 $\beta$ and thanks to the neuroanatomical RHT-SCN-PVN-NTS axis. EAAT2 increases the glutamate re-uptake from the synaptic cleft to the astrocyte cytoplasm. This decreases activation of the SCN and NTS during the day resulting in an increase in BP. The opposite occurs at night. Phosphorylation of GSK-3 $\beta$ reaches a maximum at $\mathrm{ZT} 2$. The concomitant increase in the expression of EAAT2 leads to a decrease in glutamate level in the synaptic cleft. This deactivates the AMPA-R and NMDA$\mathrm{R}$ receptors as well as the post-synaptic glutamatergic neurons in both the SCN and NTS. This induces an increase in BP during the day. The circadian phosphorylation of GSK-3 $\beta$ via the canonical $\mathrm{WNT} / \beta$-catenin signaling induces the expression of EAAT2 and GS in astrocytes. This makes it possible the increase of BP during the day and consequently the increase in the entropy production rate. At night, BP and the entropy production rate both decrease, minimizing irreversible processes. The circadian BP regulation constitutes a dissipative structure that operates far from equilibrium. From a thermodynamic point of view, the presence of a CR of BP confers a favorable status. Entropy production rate decreases at night, which minimizes the production of irreversible processes during the nocturnal period of the nychthemeron. The canonical
$\mathrm{WNT} / \beta$-catenin pathway plays a major role in mediating hypertensive heart disease [132]. Disruption of any element of this cascade may help to explain the occurrence of hypertension.

Acknowledgments We would like to thank Dr. Christophe Locher, Director of the Clinical Research Center, Grand Hôpital de l'Est Francilien, Meaux, France, for his valuable support in making the necessary research facilities available for this study. The manuscript has been revised by Prof. Brian Keogh.

Author Contributions Y.L., O.S., J.-L.H., and A.V. provided substantial contributions to discussions of the manuscript content. Y.L. wrote the article. Y.L., O.S., J.-L.H., and A.V. reviewed the manuscript before submission.

\section{Compliance with Ethics Guidelines}

Conflict of Interest The authors declare no conflicts of interest relevant to this manuscript.

Human and Animal Rights and Informed Consent This article does not contain any studies with human or animal subjects performed by any of the authors.

Open Access This article is licensed under a Creative Commons Attribution 4.0 International License, which permits use, sharing, adaptation, distribution and reproduction in any medium or format, as long as you give appropriate credit to the original author(s) and the source, provide a link to the Creative Commons licence, and indicate if changes were made. The images or other third party material in this article are included in the article's Creative Commons licence, unless indicated otherwise in a credit line to the material. If material is not included in the article's Creative Commons licence and your intended use is not permitted by statutory regulation or exceeds the permitted use, you will need to obtain permission directly from the copyright holder. To view a copy of this licence, visit http://creativecommons.org/licenses/by/4.0/.

\section{References}

Papers of particular interest, published recently, have been highlighted as:

- Of importance

-• Of major importance

1. Cowley AW Jr. Long-term control of arterial blood pressure. Physiol Rev. 1992;72(1):231-300. https://doi.org/10.1152/ physrev.1992.72.1.231.

2. Millar-Craig MW, Bishop CN, Raftery EB. Circadian variation of blood-pressure. Lancet. 1978;1(8068):795-7. https://doi.org/10. 1016/s0140-6736(78)92998-7.

3. Weber MA, Drayer JI, Nakamura DK, Wyle FA. The circadian blood pressure pattern in ambulatory normal subjects. Am J Cardiol. 1984;54(1):115-9. https://doi.org/10.1016/00029149(84)90314-x.

4. Schneider RA, Costiloe JP. Twenty-four hour automatic monitoring of blood pressure and heart rate at work and at home. Am 
Heart J. 1975;90(6):695-702. https://doi.org/10.1016/00028703(75)90458-5.

5. Agarwal R. Regulation of circadian blood pressure: from mice to astronauts. Curr Opin Nephrol Hypertens. 2010;19(1):51-8. https://doi.org/10.1097/MNH.0b013e3283336ddb.

6. Thosar SS, Butler MP, Shea SA. Role of the circadian system in cardiovascular disease. J Clin Invest. 2018;128(6):2157-67. https://doi.org/10.1172/JCI80590.

7. Kario K. Morning surge and variability in blood pressure: a new therapeutic target? Hypertension. 2005;45(4):485-6. https://doi. org/10.1161/01.HYP.0000158313.57142.3f.

8. Ohkubo T, Hozawa A, Yamaguchi J, Kikuya M, Ohmori K, Michimata M, et al. Prognostic significance of the nocturnal decline in blood pressure in individuals with and without high 24-h blood pressure: the Ohasama study. J Hypertens. 2002;20(11): 2183-9. https://doi.org/10.1097/00004872-200211000-00017.

9. Verdecchia P, Porcellati C, Schillaci G, Borgioni C, Ciucci A, Battistelli M, et al. Ambulatory blood pressure. An independent predictor of prognosis in essential hypertension. Hypertension. 1994;24(6):793-801. https://doi.org/10.1161/01.hyp.24.6.793.

10. Verdecchia P. Prognostic value of ambulatory blood pressure : current evidence and clinical implications. Hypertension. 2000;35(3):844-51. https://doi.org/10.1161/01.hyp.35.3.844.

11. Mancia G, Parati G. Ambulatory blood pressure monitoring and organ damage. Hypertension. 2000;36(5):894-900. https://doi. org/10.1161/01.hyp.36.5.894.

12. Ben-Dov IZ, Kark JD, Ben-Ishay D, Mekler J, Ben-Arie L, Bursztyn M. Predictors of all-cause mortality in clinical ambulatory monitoring: unique aspects of blood pressure during sleep. Hypertension. 2007;49(6):1235-41. https://doi.org/10.1161/ HYPERTENSIONAHA.107.087262.

13. Pickering TG. The clinical significance of diurnal blood pressure variations. Dippers and nondippers Circulation. 1990;81(2):7002. https://doi.org/10.1161/01.cir.81.2.700

14. Muller JE, Stone PH, Turi ZG, Rutherford JD, Czeisler CA, Parker C, et al. Circadian variation in the frequency of onset of acute myocardial infarction. N Engl J Med. 1985;313(21):131522. https://doi.org/10.1056/NEJM198511213132103.

15. Elliott WJ. Circadian variation in the timing of stroke onset: a meta-analysis. Stroke. 1998;29(5):992-6. https://doi.org/10. 1161/01.str.29.5.992.

16. Hower IM, Harper SA, Buford TW. Circadian rhythms, exercise, and cardiovascular health. J Circadian Rhythms. 2018;16:7. https://doi.org/10.5334/jcr.164.

17. Takeda N, Maemura K. Circadian clock and cardiovascular disease. J Cardiol. 2011;57(3):249-56. https://doi.org/10.1016/j.jjcc. 2011.02.006

18. Reppert SM, Weaver DR. Coordination of circadian timing in mammals. Nature. 2002;418(6901):935-41. https://doi.org/10. 1038/nature00965.

19. Buijs RM, Kalsbeek A. Hypothalamic integration of central and peripheral clocks. Nat Rev Neurosci. 2001;2(7):521-6. https://doi. org/10.1038/35081582.

20. Nakagawa H, Okumura N. Coordinated regulation of circadian rhythms and homeostasis by the suprachiasmatic nucleus. Proceedings of the Japan Academy Series B, Physical and biological sciences. 2010;86(4):391-409. https://doi.org/10.2183/pjab. 86.391.

21. Kiessling S, Eichele G, Oster H. Adrenal glucocorticoids have a key role in circadian resynchronization in a mouse model of jet lag. J Clin Invest. 2010;120(7):2600-9. https://doi.org/10.1172/ JCI41192.

22. Scheer FA, Hu K, Evoniuk H, Kelly EE, Malhotra A, Hilton MF, et al. Impact of the human circadian system, exercise, and their interaction on cardiovascular function. Proc Natl Acad Sci U S A.
2010;107(47):20541-6. https://doi.org/10.1073/pnas. 1006749107.

23. Yeom JH, Sim CS, Lee J, Y un SH, Park SJ, Yoo CI, et al. Effect of shift work on hypertension: cross sectional study. Annals of occupational and environmental medicine. 2017;29:11. https://doi.org/ 10.1186/s40557-017-0166-z.

24. Lutgen V, Narasipura SD, Sharma A, Min S, Al-Harthi L. betaCatenin signaling positively regulates glutamate uptake and metabolism in astrocytes. Journal of neuroinflammation. 2016;13(1): 242. https://doi.org/10.1186/s12974-016-0691-7 Beta-catenin induces the expression of EAAT2 and GS in SCN astrocytes.

25. Iwahana E, Akiyama M, Miyakawa K, Uchida A, Kasahara J, Fukunaga K, et al. Effect of lithium on the circadian rhythms of locomotor activity and glycogen synthase kinase- 3 protein expression in the mouse suprachiasmatic nuclei. The European Journal Of Neuroscience. 2004;19(8):2281-7. https://doi.org/10.1111/j. 0953-816X.2004.03322.x In SCN, pGSK-3beta follows a circadian rhythm.

26. Iitaka C, Miyazaki K, Akaike T, Ishida N. A role for glycogen synthase kinase-3beta in the mammalian circadian clock. The Journal of biological chemistry. 2005;280(33):29397-402. https://doi.org/10.1074/jbc.M503526200 In SCN astrocytes, pGSK-3b follows a circadian rhythm.

27. Chalecka-Franaszek E, Chuang DM. Lithium activates the serine/ threonine kinase Akt-1 and suppresses glutamate-induced inhibition of Akt-1 activity in neurons. Proc Natl Acad Sci U S A. 1999;96(15):8745-50. https://doi.org/10.1073/pnas.96.15.8745.

28. Zhai Y, Sun Z, Zhang J, Kang K, Chen J, Zhang W. Activation of the TOR signalling pathway by glutamine regulates insect fecundity. Sci Rep. 2015;5:10694. https://doi.org/10.1038/srep10694.

29. Kitagishi Y, Nakanishi A, Ogura Y, Matsuda S. Dietary regulation of PI3K/AKT/GSK-3beta pathway in Alzheimer's disease. Alzheimers Res Ther. 2014;6(3):35. https://doi.org/10.1186/ alzrt265.

30. Bott AJ, Peng IC, Fan Y, Faubert B, Zhao L, Li J, et al. Oncogenic Myc induces expression of glutamine synthetase through promoter demethylation. Cell Metab. 2015;22(6):1068-77. https://doi. org/10.1016/j.cmet.2015.09.025.

31. Chen L, Yang G. Recent advances in circadian rhythms in cardiovascular system. Front Pharmacol. 2015;6:71. https://doi.org/10. 3389/fphar.2015.00071.

32. Partch CL, Green CB, Takahashi JS. Molecular architecture of the mammalian circadian clock. Trends Cell Biol. 2014;24(2):90-9. https://doi.org/10.1016/j.tcb.2013.07.002.

33. Douma LG, Gumz ML. Circadian clock-mediated regulation of blood pressure. Free Radic Biol Med. 2018;119:108-14. https:// doi.org/10.1016/j.freeradbiomed.2017.11.024.

34. Richards J, Diaz AN, Gumz ML. Clock genes in hypertension: novel insights from rodent models. Blood Pressure Monitoring. 2014;19(5):249-54. https://doi.org/10.1097/MBP. 0000000000000060 .

35. Gillette MU, Reppert SM. The hypothalamic suprachiasmatic nuclei: circadian patterns of vasopressin secretion and neuronal activity in vitro. Brain Res Bull. 1987;19(1):135-9. https://doi.org/ 10.1016/0361-9230(87)90176-6.

36. Bos NP, Mirmiran M. Circadian rhythms in spontaneous neuronal discharges of the cultured suprachiasmatic nucleus. Brain Res. 1990;511(1):158-62. https://doi.org/10.1016/0006-8993(90) 90235-4.

37. Mirmiran M, Koster-Van Hoffen GC, Bos NP. Circadian rhythm generation in the cultured suprachiasmatic nucleus. Brain Res Bull. 1995;38(3):275-83. https://doi.org/10.1016/0361-9230(95) 00100-s.

38. Brugger P, Marktl W, Herold M. Impaired nocturnal secretion of melatonin in coronary heart disease. Lancet. 1995;345(8962): 1408. https://doi.org/10.1016/s0140-6736(95)92600-3. 
39. Goncharuk VD, van Heerikhuize J, Dai JP, Swaab DF, Buijs RM. Neuropeptide changes in the suprachiasmatic nucleus in primary hypertension indicate functional impairment of the biological clock. J Comp Neurol. 2001;431(3):320-30. https://doi.org/10. 1002/1096-9861(20010312)431:3<320::aid-cne1073>3.0.co;2-2.

40. Shaw JA, Chin-Dusting JP, Kingwell BA, Dart AM. Diurnal variation in endothelium-dependent vasodilatation is not apparent in coronary artery disease. Circulation. 2001;103(6):806-12. https:// doi.org/10.1161/01.cir.103.6.806.

41. Peters RV, Zoeller RT, Hennessey AC, Stopa EG, Anderson G, Albers HE. The control of circadian rhythms and the levels of vasoactive intestinal peptide mRNA in the suprachiasmatic nucleus are altered in spontaneously hypertensive rats. Brain Res. 1994;639(2):217-27. https://doi.org/10.1016/0006-8993(94) 91733-7.

42. Goncharuk VD, Van Heerikhuize J, Swaab DF, Buijs RM. Paraventricular nucleus of the human hypothalamus in primary hypertension: activation of corticotropin-releasing hormone neurons. J Comp Neurol. 2002;443(4):321-31. https://doi.org/10. 1002/cne.10124.

43. Mieda M, Okamoto H, Sakurai T. Manipulating the cellular circadian period of arginine vasopressin neurons alters the behavioral circadian period. Current biology : CB. 2016;26(18):2535-42. https://doi.org/10.1016/j.cub.2016.07.022.

44. van den Pol AN, Tsujimoto KL. Neurotransmitters of the hypothalamic suprachiasmatic nucleus: immunocytochemical analysis of 25 neuronal antigens. Neuroscience. 1985;15(4):1049-86. https://doi.org/10.1016/0306-4522(85)90254-4.

45. van den Pol AN. Glutamate and aspartate immunoreactivity in hypothalamic presynaptic axons. J Neurosci. 1991;11(7):2087101 .

46. Hannibal J. Neurotransmitters of the retino-hypothalamic tract. Cell Tissue Res. 2002;309(1):73-88. https://doi.org/10.1007/ s00441-002-0574-3.

47. Buijs FN, Cazarez F, Basualdo MC, Scheer FA, Perusquia M, Centurion $\mathrm{D}$, et al. The suprachiasmatic nucleus is part of a neural feedback circuit adapting blood pressure response. Neuroscience. 2014;266:197-207. https://doi.org/10.1016/j.neuroscience.2014. 02.018 This study shows a glutamatergic connection between NTS and SCN. The SCN counteracts a rise in BP induced by a vasopressive stimulus.

48. Sato MA, Menani JV, Lopes OU, Colombari E. Commissural NTS lesions and cardiovascular responses in aortic baroreceptordenervated rats. Hypertension. 1999;34(4 Pt 2):739-43. https:// doi.org/10.1161/01.hyp.34.4.739.

49. Colombari E, Sato MA, Cravo SL, Bergamaschi CT, Campos RR $\mathrm{Jr}$, Lopes OU. Role of the medulla oblongata in hypertension. Hypertension. 2001;38(3 Pt 2):549-54. https://doi.org/10.1161/ 01.hyp.38.3.549.

50. Janssen BJ, Tyssen CM, Duindam H, Rietveld WJ. Suprachiasmatic lesions eliminate 24 -h blood pressure variability in rats. Physiol Behav. 1994;55(2):307-11. https://doi.org/10. 1016/0031-9384(94)90138-4.

51. Aronin N, Sagar SM, Sharp FR, Schwartz WJ. Light regulates expression of a Fos-related protein in rat suprachiasmatic nuclei. Proc Natl Acad Sci U S A. 1990;87(15):5959-62. https://doi.org/ 10.1073/pnas.87.15.5959.

52. Buijs RM, la Fleur SE, Wortel J, Van Heyningen C, Zuiddam L, Mettenleiter TC, et al. The suprachiasmatic nucleus balances sympathetic and parasympathetic output to peripheral organs through separate preautonomic neurons. J Comp Neurol. 2003;464(1):3648. https://doi.org/10.1002/cne.10765.

53. Doi M, Takahashi Y, Komatsu R, Yamazaki F, Yamada H, Haraguchi S, et al. Salt-sensitive hypertension in circadian clock-deficient cry-null mice involves dysregulated adrenal
Hsd3b6. Nat Med. 2010;16(1):67-74. https://doi.org/10.1038/ nm.2061.

54. Cheng B, Anea CB, Yao L, Chen F, Patel V, Merloiu A, et al. Tissue-intrinsic dysfunction of circadian clock confers transplant arteriosclerosis. Proc Natl Acad Sci U S A. 2011;108(41):1714752. https://doi.org/10.1073/pnas.1112998108.

55. Kalsbeek A, Palm IF, La Fleur SE, Scheer FA, Perreau-Lenz S, Ruiter M, et al. SCN outputs and the hypothalamic balance of life. J Biol Rhythm. 2006;21(6):458-69. https://doi.org/10.1177/ 0748730406293854.

56. Kannan H, Yamashita H. Connections of neurons in the region of the nucleus tractus solitarius with the hypothalamic paraventricular nucleus: their possible involvement in neural control of the cardiovascular system in rats. Brain Res. 1985;329(1-2): 205-12. https://doi.org/10.1016/0006-8993(85)90526-8.

57. Jiang Z, Rajamanickam S, Justice NJ. Local Corticotropinreleasing factor signaling in the hypothalamic paraventricular nucleus. J Neurosci. 2018;38(8):1874-90. https://doi.org/10.1523/ JNEUROSCI.1492-17.2017.

58. Chan RK, Peto CA, Sawchenko PE. Fine structure and plasticity of barosensitive neurons in the nucleus of solitary tract. J Comp Neurol. 2000;422(3):338-51.

59. Weston M, Wang H, Stornetta RL, Sevigny CP, Guyenet PG. Fos expression by glutamatergic neurons of the solitary tract nucleus after phenylephrine-induced hypertension in rats. J Comp Neurol. 2003;460(4):525-41. https://doi.org/10.1002/cne.10663.

60. Nagai K, Nagai N, Sugahara K, Niijima A, Nakagawa H. Circadian rhythms and energy metabolism with special reference to the suprachiasmatic nucleus. Neurosci Biobehav Rev. 1994;18(4):579-84. https://doi.org/10.1016/0149-7634(94) 90014-0.

61. Nagai K, Nagai N, Shimizu K, Chun S, Nakagawa H, Niijima A. SCN output drives the autonomic nervous system: with special reference to the autonomic function related to the regulation of glucose metabolism. Prog Brain Res. 1996;111:253-72. https:// doi.org/10.1016/s0079-6123(08)60413-6.

62. Niijima A, Nagai K, Nagai N, Nakagawa H. Light enhances sympathetic and suppresses vagal outflows and lesions including the suprachiasmatic nucleus eliminate these changes in rats. J Auton Nerv Syst. 1992;40(2):155-60. https://doi.org/10.1016/01651838(92)90026-d.

63. Niijima A, Nagai K, Nagai N, Akagawa H. Effects of light stimulation on the activity of the autonomic nerves in anesthetized rats. Physiol Behav. 1993;54(3):555-61. https://doi.org/10.1016/00319384(93)90249-f.

64. Sayk F, Becker C, Teckentrup C, Fehm HL, Struck J, Wellhoener JP, et al. To dip or not to dip: on the physiology of blood pressure decrease during nocturnal sleep in healthy humans. Hypertension. 2007;49(5):1070-6. https://doi.org/10.1161/ HYPERTENSIONAHA.106.084343.

65. Lambert EA, Chatzivlastou K, Schlaich M, Lambert G, Head GA. Morning surge in blood pressure is associated with reactivity of the sympathetic nervous system. Am J Hypertens. 2014;27(6): 783-92. https://doi.org/10.1093/ajh/hpt273.

66. Colwell CS. Linking neural activity and molecular oscillations in the SCN. Nat Rev Neurosci. 2011;12(10):553-69. https://doi.org/ $10.1038 / \mathrm{nrn} 3086$.

67. Kurabayashi N, Hirota T, Sakai M, Sanada K, Fukada Y. DYRK1A and glycogen synthase kinase 3beta, a dual-kinase mechanism directing proteasomal degradation of CRY2 for circadian timekeeping. Mol Cell Biol. 2010;30(7):1757-68. https:// doi.org/10.1128/MCB.01047-09.

68. Sahar S, Zocchi L, Kinoshita C, Borrelli E, Sassone-Corsi P. Regulation of BMAL1 protein stability and circadian function by GSK3beta-mediated phosphorylation. PLoS One. 2010;5(1): e8561. https://doi.org/10.1371/journal.pone.0008561. 
69. Paul JR, Johnson RL, Jope RS, Gamble KL. Disruption of circadian rhythmicity and suprachiasmatic action potential frequency in a mouse model with constitutive activation of glycogen synthase kinase 3. Neuroscience. 2012;226:1-9. https://doi.org/10. 1016/j.neuroscience.2012.08.047.

70. Paul JR, DeWoskin D, McMeekin LJ, Cowell RM, Forger DB, Gamble KL. Regulation of persistent sodium currents by glycogen synthase kinase 3 encodes daily rhythms of neuronal excitability. Nat Commun. 2016;7:13470. https://doi.org/10.1038/ ncomms 13470 .

71. Paul JR, McKeown AS, Davis JA, Totsch SK, Mintz EM, Kraft TW, et al. Glycogen synthase kinase 3 regulates photic signaling in the suprachiasmatic nucleus. Eur J Neurosci. 2017;45(8):110210. https://doi.org/10.1111/ejn.13549.

72. Czeisler CA. The effect of light on the human circadian pacemaker. CIBA Found Symp. 1995;183:254-90; discussion 90-302. https://doi.org/10.1002/9780470514597.ch14.

73. Golombek DA, Rosenstein RE. Physiology of circadian entrainment. Physiol Rev. 2010;90(3):1063-102. https://doi.org/10. 1152/physrev.00009.2009.

74. Liou SY, Shibata S, Iwasaki K, Ueki S. Optic nerve stimulationinduced increase of release of $3 \mathrm{H}$-glutamate and $3 \mathrm{H}$-aspartate but not 3H-GABA from the suprachiasmatic nucleus in slices of rat hypothalamus. Brain Res Bull. 1986;16(4):527-31. https://doi. org/10.1016/0361-9230(86)90182-6.

75. Shibata S, Liou SY, Ueki S. Influence of excitatory amino acid receptor antagonists and of baclofen on synaptic transmission in the optic nerve to the suprachiasmatic nucleus in slices of rat hypothalamus. Neuropharmacology. 1986;25(4):403-9. https:// doi.org/10.1016/0028-3908(86)90235-2.

76. Colwell CS, Menaker M. NMDA as well as non-NMDA receptor antagonists can prevent the phase-shifting effects of light on the circadian system of the golden hamster. J Biol Rhythm. 1992;7(2): 125-36. https://doi.org/10.1177/074873049200700204.

77. Colwell CS. NMDA-evoked calcium transients and currents in the suprachiasmatic nucleus: gating by the circadian system. Eur J Neurosci. 2001;13(7):1420-8. https://doi.org/10.1046/j.0953816x.2001.01517.x.

78. Cervena K, Pacesova D, Spisska V, Bendova Z. Delayed effect of the light pulse on phosphorylated ERK1/2 and GSK3beta kinases in the ventrolateral suprachiasmatic nucleus of rat. Journal of molecular neuroscience : MN. 2015;56(2):371-6. https://doi.org/10. 1007/s12031-015-0563-0.

79. Jones JR, Tackenberg MC, McMahon DG. Manipulating circadian clock neuron firing rate resets molecular circadian rhythms and behavior. Nat Neurosci. 2015;18(3):373-5. https://doi.org/10. 1038/nn.3937.

80. Bedrosian TA, Weil ZM, Nelson RJ. Chronic dim light at night provokes reversible depression-like phenotype: possible role for TNF. Mol Psychiatry. 2013;18(8):930-6. https://doi.org/10.1038/ mp.2012.96.

81. Fonken LK, Aubrecht TG, Melendez-Fernandez OH, Weil ZM, Nelson RJ. Dim light at night disrupts molecular circadian rhythms and increases body weight. J Biol Rhythm. 2013;28(4): 262-71. https://doi.org/10.1177/0748730413493862.

82. Fonken LK, Nelson RJ. The effects of light at night on circadian clocks and metabolism. Endocr Rev. 2014;35(4):648-70. https:// doi.org/10.1210/er.2013-1051.

83. Dauchy RT, Xiang S, Mao L, Brimer S, Wren MA, Yuan L, et al. Circadian and melatonin disruption by exposure to light at night drives intrinsic resistance to tamoxifen therapy in breast cancer. Cancer Res. 2014;74(15):4099-110. https://doi.org/10.1158/ 0008-5472.CAN-13-3156.

84. Clevers H. Wnt/beta-catenin signaling in development and disease. Cell. 2006;127(3):469-80.
85. Heuberger J, Birchmeier W. Interplay of cadherin-mediated cell adhesion and canonical wnt signaling. Cold Spring Harb Perspect Biol. 2010;2(2):a002915.

86. Lecarpentier Y, Claes V, Duthoit G, Hebert JL. Circadian rhythms, Wnt/beta-catenin pathway and PPAR alpha/gamma profiles in diseases with primary or secondary cardiac dysfunction. Frontiers in physiology. 2014;5:429. https://doi.org/10.3389/ fphys.2014.00429.

87. Vallee A, Lecarpentier Y, Vallee JN. Circadian rhythms and energy metabolism reprogramming in Parkinson's disease. Current issues in Molecular Biology. 2019;31:21-44. https://doi.org/10. 21775/cimb.031.021.

88. Besing RC, Paul JR, Hablitz LM, Rogers CO, Johnson RL, Young $\mathrm{ME}$, et al. Circadian rhythmicity of active GSK3 isoforms modulates molecular clock gene rhythms in the suprachiasmatic nucleus. J Biol Rhythm. 2015;30(2):155-60. https://doi.org/10.1177/ 0748730415573167

89. Kaladchibachi SA, Doble B, Anthopoulos N, Woodgett JR, Manoukian AS. Glycogen synthase kinase 3, circadian rhythms, and bipolar disorder: a molecular link in the therapeutic action of lithium. J Circadian Rhythms. 2007;5:3. https://doi.org/10.1186/ 1740-3391-5-3.

90. Spengler ML, Kuropatwinski KK, Schumer M, Antoch MP. A serine cluster mediates BMAL1-dependent CLOCK phosphorylation and degradation. Cell Cycle. 2009;8(24):4138-46. https://doi. org/10.4161/cc.8.24.10273.

91. Brancaccio M, Patton AP, Chesham JE, Maywood ES, Hastings MH. Astrocytes control circadian timekeeping in the suprachiasmatic nucleus via glutamatergic signaling. Neuron. 2017;93(6): 1420-35 e5. https://doi.org/10.1016/j.neuron.2017.02.030.

92. Tso CF, Simon T, Greenlaw AC, Puri T, Mieda M, Herzog ED. Astrocytes regulate daily rhythms in the suprachiasmatic nucleus and behavior. Current biology : CB. 2017;27(7):1055-61. https:// doi.org/10.1016/j.cub.2017.02.037.

93. Jensen AA, Fahlke C, Bjorn-Yoshimoto WE, Bunch L. Excitatory amino acid transporters: recent insights into molecular mechanisms, novel modes of modulation and new therapeutic possibilities. Curr Opin Pharmacol. 2015;20:116-23. https://doi.org/10. 1016/j.coph.2014.10.008.

94. Norenberg MD, Martinez-Hernandez A. Fine structural localization of glutamine synthetase in astrocytes of rat brain. Brain Res. 1979;161(2):303-10. https://doi.org/10.1016/0006-8993(79) 90071-4.

95. Lauriat TL, McInnes LA. EAAT2 regulation and splicing: relevance to psychiatric and neurological disorders. Mol Psychiatry. 2007;12(12):1065-78. https://doi.org/10.1038/sj.mp.4002065.

96. Kim K, Lee SG, Kegelman TP, Su ZZ, Das SK, Dash R, et al. Role of excitatory amino acid transporter-2 (EAAT2) and glutamate in neurodegeneration: opportunities for developing novel therapeutics. J Cell Physiol. 2011;226(10):2484-93. https://doi. org/10.1002/jcp.22609.

97. Sitcheran R, Gupta P, Fisher PB, Baldwin AS. Positive and negative regulation of EAAT2 by NF-kappaB: a role for N-myc in TNFalpha-controlled repression. EMBO J. 2005;24(3):510-20. https://doi.org/10.1038/sj.emboj.7600555.

98. Su ZZ, Leszczyniecka M, Kang DC, Sarkar D, Chao W, Volsky DJ, et al. Insights into glutamate transport regulation in human astrocytes: cloning of the promoter for excitatory amino acid transporter 2 (EAAT2). Proc Natl Acad Sci U S A. 2003;100(4):195560. https://doi.org/10.1073/pnas.0136555100.

99. Narasipura SD, Henderson LJ, Fu SW, Chen L, Kashanchi F, AlHarthi L. Role of beta-catenin and TCF/LEF family members in transcriptional activity of HIV in astrocytes. J Virol. 2012;86(4): 1911-21. https://doi.org/10.1128/JVI.06266-11.

100. Orellana AM, Vasconcelos AR, Leite JA, de Sa LL, Andreotti DZ, Munhoz CD, et al. Age-related neuroinflammation and changes in 
AKT-GSK-3beta and WNT/ beta-CATENIN signaling in rat hippocampus. Aging. 2015;7(12):1094-111. https://doi.org/10. 18632/aging. 100853 .

101. Ernst T, Jiang CS, Nakama H, Buchthal S, Chang L. Lower brain glutamate is associated with cognitive deficits in HIV patients: a new mechanism for HIV-associated neurocognitive disorder. Journal of magnetic resonance imaging : JMRI. 2010;32(5): 1045-53. https://doi.org/10.1002/jmri.22366.

102. Audard V, Cavard C, Richa H, Infante M, Couvelard A, Sauvanet A, et al. Impaired E-cadherin expression and glutamine synthetase overexpression in solid pseudopapillary neoplasm of the pancreas. Pancreas. 2008;36(1):80-3. https://doi.org/10.1097/mpa. 0b013e318137a9da.

103. Kruithof-de Julio M, Labruyere WT, Ruijter JM, Vermeulen JL, Stanulovic V, Stallen JM, et al. The RL-ET-14 cell line mediates expression of glutamine synthetase through the upstream enhancer/promoter region. J Hepatol. 2005;43(1):126-31. https:// doi.org/10.1016/j.jhep.2005.01.036.

104. Cadoret A, Ovejero C, Terris B, Souil E, Levy L, Lamers WH, et al. New targets of beta-catenin signaling in the liver are involved in the glutamine metabolism. Oncogene. 2002;21(54):8293-301. https://doi.org/10.1038/sj.onc. 1206118.

105. Mohamed MA, Barker PB, Skolasky RL, Selnes OA, Moxley RT, Pomper MG, et al. Brain metabolism and cognitive impairment in HIV infection: a 3-T magnetic resonance spectroscopy study. Magn Reson Imaging. 2010;28(9):1251-7. https://doi.org/10. 1016/j.mri.2010.06.007.

106. Sailasuta N, Shriner K, Ross B. Evidence of reduced glutamate in the frontal lobe of HIV-seropositive patients. NMR Biomed. 2009;22(3):326-31. https://doi.org/10.1002/nbm.1329.

107. Meisner F, Neuen-Jacob E, Sopper S, Schmidt M, Schlammes S, Scheller C, et al. Disruption of excitatory amino acid transporters in brains of SIV-infected rhesus macaques is associated with microglia activation. J Neurochem. 2008;104(1):202-9. https://doi. org/10.1111/j.1471-4159.2007.05007.x.

108. Koutsilieri E, Sopper S, Heinemann T, Scheller C, Lan J, StahlHennig C, et al. Involvement of microglia in cerebrospinal fluid glutamate increase in SIV-infected rhesus monkeys (Macaca mulatta). AIDS Res Hum Retrovir. 1999;15(5):471-7. https:/ doi.org/10.1089/088922299311222.

109. Kustova Y, Ha JH, Espey MG, Sei Y, Morse D, Basile AS. The pattern of neurotransmitter alterations in LP-BM5 infected mice is consistent with glutamatergic hyperactivation. Brain Res. 1998;793(1-2):119-26. https://doi.org/10.1016/s0006-8993(98) 00167-x.

110. Plaitakis A, Caroscio JT. Abnormal glutamate metabolism in amyotrophic lateral sclerosis. Ann Neurol. 1987;22(5):575-9. https://doi.org/10.1002/ana.410220503.

111. Rothstein JD, Martin LJ, Kuncl RW. Decreased glutamate transport by the brain and spinal cord in amyotrophic lateral sclerosis. N Engl J Med. 1992;326(22):1464-8. https://doi.org/10.1056/ NEJM199205283262204.

112. Moon RT, Brown JD, Torres M. WNTs modulate cell fate and behavior during vertebrate development. Trends in genetics : TIG. 1997;13(4):157-62. https://doi.org/10.1016/s0168-9525(97) 01093-7.

113. Torp R, Lekieffre D, Levy LM, Haug FM, Danbolt NC, Meldrum BS, et al. Reduced postischemic expression of a glial glutamate transporter, GLT1, in the rat hippocampus. Exp Brain Res. 1995;103(1):51-8. https://doi.org/10.1007/bf00241964.

114. Martin LJ, Brambrink AM, Lehmann C, Portera-Cailliau C, Koehler R, Rothstein J, et al. Hypoxia-ischemia causes abnormalities in glutamate transporters and death of astroglia and neurons in newborn striatum. Ann Neurol. 1997;42(3):335-48. https://doi. org/10.1002/ana.410420310.
115. Cisneros IE, Ghorpade A. HIV-1, methamphetamine and astrocyte glutamate regulation: combined excitotoxic implications for neuro-AIDS. Curr HIV Res. 2012;10(5):392-406.

116. Potter MC, Figuera-Losada M, Rojas C, Slusher BS. Targeting the glutamatergic system for the treatment of HIV-associated neurocognitive disorders. Journal of neuroimmune pharmacology : the official journal of the Society on NeuroImmune Pharmacology. 2013;8(3):594-607. https://doi.org/10.1007/ s11481-013-9442-z.

117. Lecarpentier Y, Vallee A. Opposite interplay between PPAR gamma and canonical Wnt/Beta-catenin pathway in amyotrophic lateral sclerosis. Front Neurol. 2016;7:100. https://doi.org/10.3389/ fneur.2016.00100.

118. Mehta A, Prabhakar M, Kumar P, Deshmukh R, Sharma PL. Excitotoxicity: bridge to various triggers in neurodegenerative disorders. Eur J Pharmacol. 2013;698(1-3):6-18. https://doi.org/ 10.1016/j.ejphar.2012.10.032

119. Vallee A, Lecarpentier Y. Alzheimer disease: crosstalk between the canonical Wnt/Beta-catenin pathway and PPARs alpha and gamma. Front Neurosci. 2016;10:459. https://oi.org/10.3389/ fnins.2016.00459.

120. Lau A, Tymianski M. Glutamate receptors, neurotoxicity and neurodegeneration. Pflugers Archiv : European journal of physiology. 2010;460(2):525-42. https://doi.org/10.1007/s00424-010-08091.

121. Vallee A, Lecarpentier Y, Guillevin R, Vallee JN. Circadian rhythms, neuroinflammation and oxidative stress in the story of Parkinson's disease. Cells. 2020;9(2). doi:https://doi.org/10.3390/ cells9020314.

122. Jin Y, Yan EZ, Fan Y, Guo XL, Zhao YJ, Zong ZH, et al. Neuroprotection by sodium ferulate against glutamate-induced apoptosis is mediated by ERK and PI3 kinase pathways. Acta Pharmacol Sin. 2007;28(12):1881-90. https://doi.org/10.1111/j. 1745-7254.2007.00634.x.

123. Zhang S, Li F, Shi Y, Li G, Du B, Liu H, et al. The relationship of non-Hodgkin's lymphoma with P16 protein expression. Hua Xi Yi Ke Da Xue Xue Bao. 1996;27(3):254-7.

124. Prigogine I. Introduction to thermodynamics of irreversible processes. New York: Wiley, J; 1967.

125. Kondepudi D, Prigogine I. Modern thermodynamics from heat engines to dissipative structures. New York: Wiley \& Sons; 1999.

126. Prigogine I, Nicolis G. Biological order, structure and instabilities. Q Rev Biophys. 1971;4(2):107-48.

127. Prigogine I. Life and physics. New perspectives Cell Biophys. 1986;9(1-2):217-24.

128. Goldbeter A. Mechanism for oscillatory synthesis of cyclic AMP in Dictyostelium discoideum. Nature. 1975;253(5492):540-2.

129. Goldbeter A. Complex oscillatory phenomena, including multiple oscillations, in regulated biochemical systems. Biomed Biochim Acta. 1985;44(6):881-9.

130. Goldbeter A. Computational approaches to cellular rhythms. Nature. 2002;420(6912):238-45.

131. Lecarpentier Y, Claes V, Krokidis X, Vallée A. Comparative statistical mechanics of muscle and non-muscle contractile systems: stationary states of near-equilibrium systems in a linear regime. Entropy Journal. 2017;19(10):558.

132. Vallee A, Levy BL, Blacher J. Interplay between the reninangiotensin system, the canonical WNT/beta-catenin pathway and PPARgamma in hypertension. Curr Hypertens Rep. 2018;20(7):62. https://doi.org/10.1007/s11906-018-0860-4.

Publisher's Note Springer Nature remains neutral with regard to jurisdictional claims in published maps and institutional affiliations. 